Article

\title{
The Spiritual Heart
}

\author{
Micheline R. Anderson
}

Spirituality Mind Body Institute, Teachers College, Columbia University, New York, NY 10027, USA; mra2159@tc.columbia.edu

Received: 12 August 2020; Accepted: 27 September 2020; Published: 4 October 2020

\begin{abstract}
The heart has been a symbol within ancient philosophy and spiritual practice for personal consciousness, wisdom, intuition and love. In recent decades, scientists with growing interest in spirituality have built a strong case for the beneficial relationship between religiosity/spirituality and physical health. Explanations for this connection have included associated health behaviors that negatively impact cardiovascular health but have failed to adequately explain away this consistent association. Here, we suggest a central and bidirectional relationship between the heart, the "Master Organ," and the phenomenology of spiritual experience. Further, we provide existing evidence for a synergistic, salutogenic relationship between robust cardiac function and spiritual wellbeing that may offer a roadmap to spiritual, psychological and physical recovery and health at the individual, interpersonal and global level.
\end{abstract}

Keywords: spirituality; heart; transcendence; neurocardiology; biofeedback; heartrate variability; psychophysiology

\section{Introduction-The Heart as the Seat of the Soul}

The heart has been conceived of throughout time and across Western and Eastern traditions as a hub of perception and sacred awareness. In ancient medical classics from Babylon, Egypt, Greece, Rome and China, it is described as the center of a system supplying life force to the body and the seat of consciousness (Acierno 1994; Lind 2015). Within traditional Chinese medicine, the heart is personified as the "emperor of all organs," responsible for the brain, consciousness and storing one's spirit (Flaws et al. 2008). In Vedantic scholarship, the heart is depicted as the vessel for the self, the source of one's nature as an embodied soul and a place for unity and connection with cosmic energy (Satchidananda 1978; Olivelle 1998). Within Judeo Christian tradition, the heart is portrayed as the site of true character of a person (Samuel, 16:7), and in portraying it so, perhaps linking it inextricably with the soul in Western culture as well. In contemporary psychology, its metaphorical and literary roots have poised the heart as the seat of spiritual practice and ritualistic healing (McClintock 2015). What links these ancient and more modern depictions of the "Master Organ" are not only the metaphorical connections to spiritual awareness, love and unity, but also that they extend beyond their historical context to current scientific inquiry that connects "heart knowing," interconnection and transcendence to cardiac function and, as an extension, to human recovery and renewal.

\section{2. "Heart knowing": The Spiritual Heart as a Perceptual and Relational Organ}

The well-established relevance of one's inner life to one's inner physiology has brought attention to the observation of biological processes associated with personal spiritual practice and beliefs. Examination of functional brain imaging, heart rate variability and other biomarkers have allowed for a closer look into the physiology of in vivo spiritual activity and associated phenomena. These inquiries have evidenced patterns of activity in central and autonomic nervous systems otherwise indicated in perception and emotion management (McClintock et al. 2019; Miller et al. 2019, 2014; 
Childre and McCraty 2001). Although the brain is often designated as the source for attention regulation, the heart has been indicated as having a larger role than previously thought in regulating both attention and emotion driven responses to stress (Frysinger and Harper 1990; Porges 2007; Sandman et al. 1982; Suess et al. 1994). Not only does the heart orchestrate system-wide processes in the body via afferent neurons directing digestion and hormone production but there is now evidence that it directly influences areas of the brain integral to emotion production and regulation (Cameron 2001; Garfinkel and Critchley 2016; Gray et al. 2012; Zhang et al. 1986). The construction of emotional experience is not only influenced via the heart-brain axis, but via neurons that stem from the heart itself. This influence is significant in that spirituality and emotions (and thus cardiac function) are inextricably linked. Specifically, it is well established that spirituality and spiritual experiences themselves are intertwined with the generation of positive emotions such as awe, appreciation and joy (Fredrickson 2013; Smith et al. 2012) and that these types of emotions are associated directly with robust patterns of cardiovascular activity (McCraty and Tomasino 2006). It has also been observed that during optimal cardiac activity captured during biofeedback, individuals commonly report feelings of transcendence and deep connection and unity with the Creator (Childre and McCraty 2001). Further, pre-stimulus forms of perception including intuition, have been shown to initiate in the heart (McCraty et al. 2004a, 2004b; Thayer and Ruiz-Padial 2006) providing biological evidence of "heart knowing," a metaphor for spiritual perception and sacred wisdom that transcends intellectual and academic forms of knowing (Miller 2016). That the biological initiation of spiritually related emotional and transcendent experience as well as preconscious knowing has been localized to the heart very much suggests that the heart may house, after all, the seat of the soul.

There is also evidence that this cardiac activity (in the form of electromagnetic energy) can be shared among individuals and within groups, can influence brain and cardiac rhythms and is theorized to be the mechanism between love and salutary health benefits (Russek and Schwartz 1994; Timofejeva et al. 2017). These synchronized energies that entrain cardiac rhythms may offer insight into shared spiritual experiences or reports of feelings of union and interconnectedness among religious and spiritual group members (Jovanov 2011; Vieten et al. 2016). Of particular relevance are data that suggest that collective energies can lead to shifts within and beyond a community (e.g., reduced political violence; Hagelin et al. 1999; Hagelin 2007). These findings suggest that the spiritual heart is open and expressive and its energy is not held within the confines of the physical body. That "heart knowing" may be shared with another during spiritually attuned moments and may be a byproduct of the entanglement of electromagnetic fields produced by cardiac energy is further support for previous characterizations of the heart as the seat of perception and connection.

\section{The Transcendent Heart: Phenomena of Spiritual Experience Induces Optimal Heart Function and Vice Versa}

With this in mind, we may then theorize about the heart's role in the salutary relationship between spirituality and health and wellbeing. Among many proposed pathways, consistent efforts to capture the embodied expression of spirit have taken the form of measurement of the heart (Bastos et al. 2018; Kirby et al. 2017; Kurita et al. 2011; Seeman et al. 2003; Tyagi and Cohen 2016). Related characteristics linked to well-developed personal spirituality including compassion, intuition, love, transcendent experience and gratitude have all been associated with, if not directly measured as, healthy tonic and phasic cardiac activity (Childre and McCraty 2001; Kirby et al. 2017; McCraty and Childre 2004; Stellar et al. 2015). Assessment of these spiritual forms of feeling and knowing as they occur suggest a bidirectional, potentially therapeutic relationship between healthy heart patterns and spiritual experience. Observed across a number of rigorous studies, an individual trained in biofeedback can invoke a psychophysiological "coherent" state, a cardiovascular rhythm described as the synchronization of mind and body, which subsequently parallels with the induction of a self-described transcendent state (Childre and McCraty 2001). Conversely, as one brings prayer, compassion, gratitude and interconnectedness into their heart center, a unique and consistently optimal 
physiological pattern emerges, perhaps indicating a spiritually driven concordance of spirit, mind and body (Doufesh et al. 2014; Khanam et al. 2018; Arya et al. 2018; Chu et al. 2017). The bidirectional relationship may explain the process behind documented phenomena with ambiguous mechanisms, including how spiritual wellbeing improves/is tapped into via mind-body practiced divorced from spiritual roots (e.g., some Western forms of yoga, mindfulness) as well as how cardiovascular function is improved via spiritual practice (Benson 1996; Cobb et al. 2015).

These observations are not unique to experimentation. Thousands of years of "heart knowing" has now been brought into atomistic observation via research that suggests that the capacity for spiritual experience is inborn, innate and lies dormant until it is cultivated and developed (Kendler et al. 1997, 1999; Miller 2016). This salutogenic birthright is borne out over and again in longitudinal studies that show that highly spiritual people experience less cardiovascular disease, live longer, and survive congestive heart failure longer than less spiritual people (Chida et al. 2009; Park et al. 2016; Lee and Newberg 2005). While efforts to distill this relationship have often focused on Materialist reasons for this link such as explicit and implicit behaviors (e.g., healthy life choices and positive thinking, respectively), the "reason" for spirituality's impactful outcome on physical wellbeing has remained elusive. It has been suggested that the mechanism may lie in the perception of and felt closeness to the Transcendent (Berntson et al. 2008). In other words, the spiritual heart may have a physiological vigor and vitality that is the byproduct of the harmonization of mind, body and spirit, the dissolution of boundaries of self and other, and the connectedness and shared compassion with humanity, Nature or a Higher Power.

\section{Clinical Implications: The Spiritual Heart Chooses Renewal and Recovery}

So too can we envision how the spiritual heart can write the story of renewal and recovery. With the scope of life encompassing everything from minor daily hassles to catastrophic trauma, the heart is the conductor of the symphony of spirit-mind-body response. When threat is perceived consciously or unconsciously, it has been suggested that the prefrontal cortex becomes inactivated (Thayer and Ruiz-Padial 2006) so that the autonomic system takes over. The heart then: (1) sends out signals to the digestive tract, the limbic and endocrine system, (2) sets off the impulses that inevitably dictate an approach or avoid response and (3) constructs a system wide sequence that determines the acute and chronic consequences of each event. It is here that the heart "chooses" the outcome. Specifically, the autonomic nervous system spurs action tendencies related to emotions not limited to fear, but including positive emotions such as compassion, gratitude and love (Eisenberg et al. 1989; McCraty and Childre 2004; Porges 1998). By engaging in actions, including prayer and meditation, that build an inner life and activate the parasympathetic response, an individual is then moved toward the cultivation of outward attention, which opens the heart and the body towards love and connection rather than toward the alternative response of withdrawal and quiescence. A spiritual heart will always choose the path of love and safety and this manifests in qualitative reports of spiritual experience that map onto optimal heart rhythms (Childre and McCraty 2001). The stressed, fearful heart will perpetuate the flight or freeze pattern until the body's response to fear is shifted through intentional and often effortful re-syncing of the spirit, mind and body (Van der Kolk 2004, 2015). Indeed, studies of spiritually integrated psychotherapy, which emphasize techniques such as "listening to the heart" or connecting to heart knowing, show promise in treating populations whose disorders result in/from subjective experiences of acute isolation, withdrawal or perceived lack of love (Berrett et al. 2018; Sanders et al. 2015). These implications may be far reaching. For example, there is evidence that spiritual practice can offset the acute cardiac effects of perceived racism in an individual (Cooper et al. 2014). It is possible that improvements in cardiac activity, elicited via a deep engagement with the Transcendent, might assist in offsetting the deleterious effects of daily stressors, thus improving cardiovascular health disparities across marginalized groups. In this way, spiritual experience and expression can re-align the heart as the Master Organ and mind and spirit towards equanimity and renewal. 


\section{The Spiritual Heart Can Aid Recovery from Collective Stressors}

With the advent of technology, globalization has reached an all-time high. Near instant connection, communication and consumerism brings with it the elevation of issues of social justice but also more concerning consequences such as rampant spread of novel diseases (e.g., the COVID-19 pandemic) and climate change. While the intrapersonal impacts of spiritual practice and improved cardiac function have potential for idiographic health improvements, the interpersonal, group and collective potential of engaging with the spiritual heart is promising as well. Person-to-person, the heart has been shown to provide the strongest emission of electromagnetic energy from the body and that energy can be experienced as shared and loving with or without human touch (McCraty et al. 1998a). Beyond anecdotal accounts of shared "heart energy", remote and local forms of healing have recently been supported scientifically, with particular improvements observed in heart rate variability (Díaz-Rodríguez et al. 2011; Edwards et al. 2018; Lee et al. 2016), thus supporting the theory that electromagnetic energy produced by the heart is the mechanism for energy healing (McCraty et al. 1998a; McDonough-Means et al. 2004). In particular, the implications of this research suggest that it is not only that energy is available for exchange, but that adopting a spiritually attuned attitude of loving and caring may maximize therapeutic potential, as these subtle shifts are noted by the receiver.

Adding to the literature on local and nonlocal sharing of measured and observed energetic systems are those that suggest that, as humans, energy produced by our cardiovascular systems engage directly with the Earth's magnetic field. Specifically, fluctuations in the earth's electromagnetic energy and solar activity have been associated with individual or group cardiovascular function (Alabdulgader et al. 2018; Jaruševičius et al. 2018; McCraty and Deyhle 2015), suggesting that energetic synchronization with nature is not only experienced by those who are awakened and sensitized to these transcendent moments, but is happening all the time outside of our consciousness. Alternately, it is thought that a simultaneous, collective effort to produce physiological coherence can help to promote stability in the earth's geomagnetic field, which will have subsequent beneficial outcomes, including social coherence and cohesion on a global level (McCraty et al. 2012). While these electromagnetic influences can most certainly have adverse effects under times of stress (Timofejeva et al. 2017), it is suggested that the spiritual heart, if fostered as a collective, can serve as catalyst of global healing (for review, see McCraty and Deyhle 2015). In short, that neurovisceral phenomena manifested in the body, transmitted by the heart, experienced as spiritual awakening and associated with longevity and health can be cultivated, fostered and shared collectively suggests a direct pathway to renewal and recovery from both physical, psychological and environmental pathology on idiographic and nomothetic levels.

\section{Conclusions}

There is strong evidence that a system-wide physiological process that balances the autonomic nervous system into a parasympathetically dominated state manifests itself psychologically as positive emotional experience to include (but not limited to) interconnectedness with others, nature Higher Power (Childre and McCraty 2001). This harmonious physiological state, able to be induced again and again via the conscious bringing forth of positive emotions held sacred by spiritual traditions (love, compassion, gratitude, forgiveness) then provides an internal psychological and physiological environment ripe for the development of a personally held and experienced spirituality. As this spiritual "muscle" is strengthened, the heart, in turn is reinvigorated and sustained via enhanced heart rate variability and sympathovagal tone, building stamina and signaling through its aforementioned channels long-lasting and far-reaching effects to the brain, the internal organs and throughout the body. This type of energetic equanimity has been proposed to offset stress, improve cognitive function and ultimately ameliorate psychological and physiological distress that predicts long term negative health outcomes (McCraty et al. 1998b, 2009). 
The spiritual heart is one in which gratitude, wisdom, intuition and interconnectedness radiate in myriad ways, not merely in the metaphors of time immemorial, but with radical consequences that extend beyond one's self to other living beings, to Nature, and to the rhythms of our universe. Immediate growth and recovery may initiate at the individual level but may, if initiated en masse, eradicate social injustice, environmental degradation and bring about a "heartfelt" global spiritual awakening. Using a "heart as a spiritual organ" framework can expand the application of either body-based or spiritually-oriented treatment and prevention of stress-related mental and physical illness and help to foster spiritual development to build wellness and flourishing on an individual, group and even universal level.

Funding: This research received no external funding.

Conflicts of Interest: The author declares no conflict of interest.

\section{References}

Acierno, Louis J. 1994. The History of Cardiology. London and New York: Parthenon Publishers.

Alabdulgader, Abdullah, Rollin McCraty, Michael Atkinson, York Dobyns, Alfonsas Vainoras, Minvydas Ragulskis, and Viktor Stolc. 2018. Long-Term Study of Heart Rate Variability Responses to Changes in the Solar and Geomagnetic Environment. Scientific Reports 8: 1-14. [CrossRef] [PubMed]

Arya, Narendra Kumar, Kamlesh Singh, Anushree Malik, and Rahul Mehrotra. 2018. Effect of Heartfulness Cleaning and Meditation on Heart Rate Variability. Indian Heart Journal 70: S50-S55. [CrossRef] [PubMed]

Bastos, Marco Aurélio Vinhosa, Jr., Paulo Roberto Haidamus de Oliveira Bastos, Igraíne Helena Scholz Osório, Sérgio Augusto Monteiro Pinheiro, D. Iandoli Jr., and Giancarlo Lucchetti. 2018. Physiologic Correlates of Culture-Bound Dissociation: A Comparative Study of Brazilian Spiritist Mediums and Controls. Transcultural Psychiatry 55: 286-313. [CrossRef] [PubMed]

Benson, H. 1996. Timeless Healing: The Power and Biology of Belief. New York: Scribner.

Berntson, Gary G., Greg J. Norman, Louise C. Hawkley, and John T. Cacioppo. 2008. Spirituality and Autonomic Cardiac Control. Annals of Behavioral Medicine 35: 198-208. [CrossRef]

Berrett, Michael E., Sabree A. Crowton, and P. Scott Richards. 2018. Finding Self Again: The Dismantling of Eating Disorder and Trauma Identity. In Trauma-Informed Approaches to Eating Disorders. Edited by Andrew Seubert and Pam Virdi. New York: Springer Publishing Company, pp. 337-50.

Cameron, Oliver G. 2001. Visceral Sensory Neuroscience: Interoception. New York: Oxford University Press.

Chida, Yoichi, Andrew Steptoe, and Lynda H. Powell. 2009. Religiosity/Spirituality and Mortality. Psychotherapy and Psychosomatics 78: 81-90. [CrossRef]

Childre, Doc, and Rollin McCraty. 2001. Psychophysiological Correlates of Spiritual Experience. Biofeedback 29: 13-17.

Chu, I-Hua, Wen-Lan Wu, I-Mei Lin, Yu-Kai Chang, Yuh-Jen Lin, and Pin-Chen Yang. 2017. Effects of Yoga on Heart Rate Variability and Depressive Symptoms in Women: A Randomized Controlled Trial. The Journal of Alternative and Complementary Medicine 23: 310-16. [CrossRef]

Cobb, Eleanor, Ariel Kor, and Lisa Miller. 2015. Support for Adolescent Spirituality: Contributions of Religious Practice and Trait Mindfulness. Journal of Religion and Health 54: 862-70. [CrossRef]

Cooper, Denise C., Julian F. Thayer, and Shari R. Waldstein. 2014. Coping with Racism: The Impact of Prayer on Cardiovascular Reactivity and Post-Stress Recovery in African American Women. Annals of Behavioral Medicine 47: 218-30. [CrossRef]

Díaz-Rodríguez, Lourdes, Manuel Arroyo-Morales, César Fernández-de-Las-Peñas, Francisca García-Lafuente, Carmen García-Royo, and Inmaculada Tomás-Rojas. 2011. Immediate Effects of Reiki on Heart Rate Variability, Cortisol Levels, and Body Temperature in Health Care Professionals with Burnout. Biological Research for Nursing 13: 376-82. [CrossRef]

Doufesh, Hazem, Fatimah Ibrahim, Noor Azina Ismail, and Wan Azman Wan Ahmad. 2014. Effect of Muslim Prayer (Salat) on $\alpha$ Electroencephalography and Its Relationship with Autonomic Nervous System Activity. The Journal of Alternative and Complementary Medicine 20: 558-62. [CrossRef] [PubMed] 
Edwards, Darren, Hayley Young, Annabel Curtis, and Ross Johnston. 2018. The Immediate Effect of Therapeutic Touch and Deep Touch Pressure on Range of Motion, Interoceptive Accuracy and Heart Rate Variability: A Randomized Controlled Trial with Moderation Analysis. Frontiers in Integrative Neuroscience 12: 41. [CrossRef] [PubMed]

Eisenberg, Nancy, Richard A. Fabes, Paul A. Miller, Jim Fultz, Rita Shell, Robin M. Mathy, and Ray R. Reno. 1989. Relation of Sympathy and Personal Distress to Prosocial Behavior: A Multimethod Study. Journal of Personality and Social Psychology 57: 55. [CrossRef] [PubMed]

Flaws, Robert, Michael Johnston, and Timothy Rogers. 2008. Statements of Fact in Traditional Chinese Medicine, 3rd ed. Boulder: Blue Poppy Press.

Fredrickson, Barbara L. 2013. Positive Emotions Broaden and Build. Advances in Experimental Social Psychology 47: 1-53.

Frysinger, Robert C., and Ronald M. Harper. 1990. Cardiac and Respiratory Correlations with Unit Discharge in Epileptic Human Temporal Lobe. Epilepsia 31: 162-71. [CrossRef]

Garfinkel, Sarah N., and Hugo D. Critchley. 2016. Threat and the Body: How the Heart Supports Fear Processing. Trends in Cognitive Sciences 20: 34-46. [CrossRef]

Gray, Marcus A., Felix D. Beacher, Ludovico Minati, Yoko Nagai, Andrew H. Kemp, Neil A. Harrison, and Hugo D. Critchley. 2012. Emotional Appraisal Is Influenced by Cardiac Afferent Information. Emotion 12: 180. [CrossRef]

Hagelin, John. 2007. Beyond Miracles: The Discovery of the Unified Field and Its Practical Applications to Prevent Crime, Terrorism, and International Conflict. Subtle Energies \& Energy Medicine Journal Archives 18: $39-52$.

Hagelin, John S., Maxwell V. Rainforth, Kenneth L. C. Cavanaugh, Charles N. Alexander, Susan F. Shatkin, John L. Davies, Anne O. Hughes, Emanuel Ross, and David W. Orme-Johnson. 1999. Effects of Group Practice of the Transcendental Meditation Program on Preventing Violent Crime in Washington, DC: Results of the National Demonstration Project, June-July 1993. Social Indicators Research 47: 153-201.

Jaruševičius, Gediminas, Tautvydas Rugelis, Rollin McCraty, Mantas Landauskas, Kristina Berškienè, and Alfonsas Vainoras. 2018. Correlation between Changes in Local Earth's Magnetic Field and Cases of Acute Myocardial Infarction. International Journal of Environmental Research and Public Health 15: 399. [CrossRef]

Jovanov, Emil. 2011. On Physiological Bases of States of Expanded Consciousness. In States of Consciousness. Edited by Dean Cvetkovic and Irena Cosic. Berlin: Springer, pp. 203-21.

Kendler, Kenneth S., Charles O. Gardner, and Carol A. Prescott. 1997. Religion, psychopathology, and substance use and abuse: A multimeasure, genetic-epidemiologic study. The American Journal of Psychiatry 154: 322-29.

Kendler, Kenneth S., M. C. Neale, P. Sullivan, L. A. Corey, C. O. Gardner, and C. A. Prescott. 1999. A population-based twin study in women of smoking initiation and nicotine dependence. Psychological Medicine 29: 299-308. [CrossRef] [PubMed]

Khanam, Farzana, Md Asadur Rahman, and Mohiuddin Ahmad. 2018. Evaluating Alpha Relative Power of EEG Signal during Psychophysiological Activities in Salat. Paper presented at the 2018 International Conference on Innovations in Science, Engineering and Technology (ICISET), Chittagong, Bangladesh, October 27-28; pp. 195-200.

Kirby, James N., James R. Doty, Nicola Petrocchi, and Paul Gilbert. 2017. The Current and Future Role of Heart Rate Variability for Assessing and Training Compassion. Frontiers in Public Health 5: 40. [CrossRef]

Kurita, Akira, Bonpei Takase, Naosuke Shinagawa, Eitaro Kodani, Kaoru Okada, Shinichiro Iwahara, Yoshiki Kusama, and Hirotsugu Atarashi. 2011. Spiritual Activation in Very Elderly Individuals Assessed as Heart Rate Variability and Plasma IL/10/IL-6 Ratios. International Heart Journal 52: 299-303. [CrossRef] [PubMed]

Lee, Bruce Y., and Andrew B. Newberg. 2005. Religion and Health: A Review and Critical Analysis. Zygon ${ }^{\circledR} 40$ : 443-68. [CrossRef]

Lee, Hojung, Tae-Hun Kim, and Jungtae Leem. 2016. Acupuncture for Heart Failure: A Systematic Review of Clinical Studies. International Journal of Cardiology 222: 321-31. [CrossRef]

Lind, Richard E. 2015. The Seat of Consciousness in Ancient Literature. Jefferson: McFarland.

McClintock, Clayton H. 2015. Opening the Heart: A Spirituality of Gratitude. Spirituality in Clinical Practice 2: 21-22. [CrossRef] 
McClintock, Clayton H., Patrick D. Worhunsky, Iris M. Balodis, Rajita Sinha, Lisa Miller, and Marc N. Potenza. 2019. How Spirituality May Mitigate against Stress and Related Mental Disorders: A Review and Preliminary Neurobiological Evidence. Current Behavioral Neuroscience Reports 6: 253-62. [CrossRef]

McCraty, Rollin, Mike Atkinson, and Raymond Trevor Bradley. 2004a. Electrophysiological Evidence of Intuition: Part 1. The Surprising Role of the Heart. The Journal of Alternative E Complementary Medicine 10: 133-43.

McCraty, Rollin, Mike Atkinson, and Raymond Trevor Bradley. 2004b. “Electrophysiological Evidence of Intuition: Part 2. A System-Wide Process?". The Journal of Alternative E Complementary Medicine 10: 325-36.

McCraty, Rollin, Mike Atkinson, Dana Tomasino, and Raymond Trevor Bradley. 2009. The Coherent Heart Heart-Brain Interactions, Psychophysiological Coherence, and the Emergence of System-Wide Order. Integral Review: A Transdisciplinary Journal for New Thought, Research, Praxis 5: 10-115.

McCraty, Rollin, Mike Atkinson, Dana Tomasino, and William A. Tiller. 1998a. The Electricity of Touch: Detection and Measurement of Cardiac Energy Exchange between People. In Brain and Values: Is a Biological Science of Values Possible. Edited by K. H. Pribram. Mahwah: Lawrence Erlbaum Associates, pp. 359-79.

McCraty, Rollin, Bob Barrios-Choplin, Deborah Rozman, Mike Atkinson, and Alan D. Watkins. 1998b. The Impact of a New Emotional Self-Management Program on Stress, Emotions, Heart Rate Variability, DHEA and Cortisol. Integrative Physiological and Behavioral Science 33: 151-70. [CrossRef] [PubMed]

McCraty, Rollin, and Doc Childre. 2004. The Grateful Heart the Psychophysiology of Appreciation. In The Psychology of Gratitude. Edited by R. A. Emmons and Michael E. McCullough. New York: Oxford University Press, pp. 240-65.

McCraty, Rollin, and A. Deyhle. 2015. The Global Coherence Initiative: Investigating the Dynamic Relationship between People and Earth's Energetic Systems. Bioelectromagnetic and Subtle Energy Medicine 2: 411-25.

McCraty, Rollin, Annette Deyhle, and Doc Childre. 2012. The Global Coherence Initiative: Creating a Coherent Planetary Standing Wave. Global Advances in Health and Medicine 1: 64-77. [CrossRef] [PubMed]

McCraty, Rollin, and Dana Tomasino. 2006. Psychophysiological Coherence. Stress Health Dis 5: 288.

McDonough-Means, Sharon I., Mary Jo Kreitzer, and Iris R. Bell. 2004. Fostering a Healing Presence and Investigating Its Mediators. Journal of Alternative E Complementary Medicine 10: S25-S41.

Miller, Lisa. 2016. The Spiritual Child: The New Science on Parenting for Health and Lifelong Thriving. New York: St. Martin's Press.

Miller, Lisa, Iris M. Balodis, Clayton H. McClintock, Jiansong Xu, Cheryl M. Lacadie, Rajita Sinha, and Marc N. Potenza. 2019. Neural Correlates of Personalized Spiritual Experiences. Cerebral Cortex 29: 2331-38. [CrossRef] [PubMed]

Miller, Lisa, Ravi Bansal, Priya Wickramaratne, Xuejun Hao, Craig E. Tenke, Myrna M. Weissman, and Bradley S. Peterson. 2014. Neuroanatomical Correlates of Religiosity and Spirituality: A Study in Adults at High and Low Familial Risk for Depression. JAMA Psychiatry 71: 128-35. [CrossRef]

Olivelle, Patrick. 1998. The Early Upanishads: Annotated Text and Translation. New York: Oxford University Press.

Park, Crystal L., Carolyn M. Aldwin, Soyoung Choun, Damodhar P. Suresh, and Deborah Bliss. 2016. Spiritual Peace Predicts 5-Year Mortality in Congestive Heart Failure Patients. Health Psychology 35: 203. [CrossRef]

Porges, Stephen W. 1998. Love: An Emergent Property of the Mammalian Autonomic Nervous System. Psychoneuroendocrinology 23: 837-61. [CrossRef]

Porges, Stephen W. 2007. The Polyvagal Perspective. Biological Psychology 74: 116-43. [CrossRef]

Russek, Linda G., and Gary E. Schwartz. 1994. Interpersonal Heart-Brain Registration and the Perception of Parental Love: A 42 Year Follow-up of the Harvard Mastery of Stress Study. Subtle Energies \& Energy Medicine Journal Archives 5: 195-208.

Sanders, Peter W., P. Scott Richards, Jason A. McBride, Troy Lea, Randy K. Hardman, and Daniel V. Barnes. 2015. Processes and Outcomes of Theistic Spiritually Oriented Psychotherapy: A Practice-Based Evidence Investigation. Spirituality in Clinical Practice 2: 180. [CrossRef]

Sandman, C. A., B. B. Walker, and C. Berka. 1982. Influence of Afferent Cardiovascular Feedback on Behavior and the Cortical Evoked Potential. In Perspectives in Cardiovascular Psychophysiology. New York: The Guilford Press. Satchidananda, Swami. 1978. The Yoga Sutras of Patanjali. Buckingham: Integral Yoga Publications.

Seeman, Teresa E., Linda Fagan Dubin, and Melvin Seeman. 2003. Religiosity/Spirituality and Health: A Critical Review of the Evidence for Biological Pathways. American Psychologist 58: 53. [CrossRef] [PubMed] 
Smith, Bruce W., J. Alexis Ortiz, Kathryn T. Wiggins, Jennifer F. Bernard, and Jeanne Dalen. 2012. Spirituality, Resilience, and Positive Emotions. In The Oxford Hanbook of Psychology and Spirituality. Edited by Lisa J. Miller. New York: Oxford University Press, pp. 437-54.

Stellar, Jennifer E., Adam Cohen, Christopher Oveis, and Dacher Keltner. 2015. Affective and Physiological Responses to the Suffering of Others: Compassion and Vagal Activity. Journal of Personality and Social Psychology 108: 572. [CrossRef] [PubMed]

Suess, Patricia E., Stephen W. Porges, and Dana J. Plude. 1994. Cardiac Vagal Tone and Sustained Attention in School-age Children. Psychophysiology 31: 17-22. [CrossRef]

Thayer, Julian F., and Elisabeth Ruiz-Padial. 2006. Neurovisceral Integration, Emotions and Health: An Update. International Congress Series 1287: 122-27. [CrossRef]

Timofejeva, Inga, Rollin McCraty, Mike Atkinson, Roza Joffe, Alfonsas Vainoras, Abdullah A. Alabdulgader, and Minvydas Ragulskis. 2017. Identification of a Group's Physiological Synchronization with Earth's Magnetic Field. International Journal of Environmental Research and Public Health 14: 998. [CrossRef] [PubMed]

Tyagi, Anupama, and Marc Cohen. 2016. Yoga and Heart Rate Variability: A Comprehensive Review of the Literature. International Journal of Yoga 9: 97-113. [CrossRef]

Van der Kolk, Bessel A. 2004. Psychobiology of Posttraumatic Stress Disorder. In Textbook of Biological Psychiatry. Edited by Jaak Panksepp. Hoboken: Wiley-Liss, pp. 319-44.

Van der Kolk, Bessel A. 2015. The Body Keeps the Score: Brain, Mind, and Body in the Healing of Trauma. New York: Penguin Books.

Vieten, Cassandra, Shelley Scammell, Alan Pierce, Ron Pilato, Ingrid Ammondson, Kenneth I. Pargament, and David Lukoff. 2016. Competencies for Psychologists in the Domains of Religion and Spirituality. Spirituality in Clinical Practice 3: 92-114. [CrossRef]

Zhang, Jing-Xi, Ronald M. Harper, and Robert C. Frysinger. 1986. Respiratory Modulation of Neuronal Discharge in the Central Nucleus of the Amygdala during Sleep and Waking States. Experimental Neurology 91: 193-207. [CrossRef]

(C) 2020 by the author. Licensee MDPI, Basel, Switzerland. This article is an open access article distributed under the terms and conditions of the Creative Commons Attribution (CC BY) license (http://creativecommons.org/licenses/by/4.0/). 